\title{
Thermal, Mechanical and Rheological Properties of Low Density/Linear Low Density Polyethylene Blend for Packing Application
}

\author{
F. Al-Attar, M. Alsamhan*, A. Al-Banna, J. Samuel \\ Polymeric Products and Customization Program, Petroleum Research Center, Kuwait Institute for Scientific Research, \\ Kuwait City, Kuwait \\ Email: *msamhan@kisr.edu.kw
}

How to cite this paper: Al-Attar, F., Alsamhan, M., Al-Banna, A. and Samuel, J. (2018) Thermal, Mechanical and Rheological Properties of Low Density/Linear Low Density Polyethylene Blend for Packing Application. Journal of Materials Science and Chemical Engineering, 6, 32-38. https://doi.org/10.4236/msce.2018.61005

Received: December 17, 2017

Accepted: January 1, 2018

Published: January 4, 2018

\begin{abstract}
Packaging is the subject of considerable commercial development by a variety of organizations around the world. In this study the mechanical, thermal and rheological properties were investigated for different blend ratios of low density polyethylene (LDPE) and linear low density polyethylene (LLDPE). The weight percent of the LDPEs used in the blends were 50,60, 70, 80 and 90 . The polymer blends were prepared in a twin screw extruder to produce a thin sheet (1-mm thickness) similar to the packaging grade. Tensile results showed that the 50/50 composition exhibited the highest stress at break, where the differential scanning calorimetry results indicated a co-crystalline phase in some blends. The results produced by the rheometer revealed the LLDPE effect over the complex viscosity and consequently blend easy processing. The present study conclusively demonstrates that at low weight percent of linear low density polyethylene in the blend displays better properties for packaging application.
\end{abstract}

\section{Keywords}

PE Blend, Packaging, Tensile Properties, Morphology

\section{Introduction}

Packaging is a technology of enclosing or covering products for distribution, storage, sale, and use. Packaging also refers to the process of design, evaluation, and production of packages. Packaging can be described as a coordinated system of preparing goods for transport, warehousing, logistics, sale, and end use. In terms of food packaging, polymer properties play an important role for improving the quality and shelf life of the food [1]. A polymer blend or polymer mix- 
ture is defined as a new class of materials, in which two polymers at least are blended together to create a new material with different physical properties. Mainly, this is done in order to improve and enhance certain properties such as thermal and barrier [2]. Most of the previous studies discussed the blend of linear low density polyethylene/low density polyethylene (LLDP/LDP) from the point view to enhance general properties of the polymer. However, this study was taken with the understanding of such blend one step farther by linking it to food packaging application. Most studies agreed that LLDPE/LDPE are miscible blends at low LDPE contents, which become immiscible at higher LDPE. Hexene comonomer promotes immiscibility; whereas, octene comonomer promotes miscibility, in addition, low molecular weight LLDPEs promote miscibility better than high Mw ones. In a recent review, Zhao and Choi [3] reported that LLDPE/ LDPE blends are immiscible in the melt state, with LCB being the determining factor of their immiscibility behavior. Recently, Wagner [4] performed a quantitative analysis of melt elongational behavior of LLDPE/LDPE blends. They reported that the complex behavior of these blends can be understood by assuming the existence of two phases; one phase composed of the highly branched low Mw chains of both polyethylenes, and a second phase composed of the high $\mathrm{Mw}$ chains (mostly linear) of both polyethylenes. Differential scanning calorimetry (DSC) thermograms of LLDPE/LDPE blends reported by Fang [5] supported the existence of a third phase composed of chains from the two polyethylenes that have the ability to cocrystallize; additionally, enhancement in the crystallization behavior of BPE blended with linear polyethylene (LPE) was explained in terms of co-crystallization due to the incorporation of the linear segments of BPE into rich LPE lamellae and the segregation of the most branched chains.

Further investigation and research will be needed in order to explore the compatibility and performance of LLDEP/LDPE blend for packaging application. This project focused on the aim of blending different ratios of these polymers and by optimizing their suitability for food packaging by testing their mechanical and physical properties. This paper presents the results of different LDPE/LLDPE blends for food packging application, results include scanning electron microscopy (SEM) and measurement of tensile properties. The foundmental discussion of the thermal stability of the blends was obtained from Differential Scanning Calorimetry (DSC).

\section{Experimental}

\subsection{Materials}

The polymer samples LDPE and LLDPE were received from companies Equate and Qapco, respectively, and the material properties of each sample are given in Table 1.

\subsection{Preparation}

Polymer pellets were dried at $80^{\circ} \mathrm{C}$ in a hot air oven. Immediately, all materials 
Table 1. Material properties.

\begin{tabular}{ccccccc}
\hline Name & Grade & Melt Flow Index & Density & $\begin{array}{c}\text { Melting } \\
\text { Point }\end{array}$ & Haze (\%) & Gloss \\
\hline LDPE & FB3003 & $0.30 \mathrm{~g} / 10 \mathrm{~min}$ & $0.920 \mathrm{~g} / \mathrm{cm}^{3}$ & $109^{\circ} \mathrm{C}$ & 13 & $40 \mathrm{GU}$ \\
LLDPE & EFDC-7050 & $2.0 \mathrm{~g} / 10 \mathrm{~min}$ & $0.918 \mathrm{~g} / \mathrm{cm}^{3}$ & $124^{\circ} \mathrm{C}$ & 14 & $50 \mathrm{GU}$ \\
\hline
\end{tabular}

were sealed in plastic bags and kept in desiccators prior to the blending. The samples were compounded by simultaneously adding all the components to the twin screw extruder. The barrel temperature profiles during compounding of all blends were varied from $175^{\circ} \mathrm{C}$ to $195^{\circ} \mathrm{C}$ at the feed section and from $160^{\circ} \mathrm{C}$ to $200^{\circ} \mathrm{C}$ at the die's head. This variation was done in order to optimize the processing conditions. The screw rotation speed of the extruder was fixed at 40 $\mathrm{rpm}$ to ensure more residence time for compounding without degrading the material. The samples in sheet forms with 1-mm thickness, then cooled to $25^{\circ} \mathrm{C}$ for a period of 24 hour. Then the specimens were prepared in desired dimensions for instrumental analysis. Mechanical, thermal and morphological properties were tested according to ASTM standards such as ASTM D 638 [6] for mechanical properties and ASTM D 3850-200 [7] for thermal properties.

\section{Results and Discussion}

\subsection{Mechanical Invistigation}

The mechanical properties of the blend samples were studied using a Testometric Machine (M250-AG1) with a load cell of $2.5-\mathrm{KN}$ capacities. The gauge length between the jaws at the start of each test was adjusted to $40 \mathrm{~mm}$, and the measurements were carried out at a crosshead speed of $500 \mathrm{~mm} \cdot \mathrm{min}^{-1}$. Properties of stress at Peak, stress at break, youngs modulus and elongation at break were evaluated for the different blend compositions, and the results are summarized in Table 2. Elongation at break results showed a strong influence of LLDPE on increasing the values, however in the $30 \%$ and $40 \%$ it is realized that the blend was less influenced by the LLDPE breaking strength this could be attributed to the entanglements between the short and long side chain branching. The composition LDPE/LLDPE (70/30) showed comparatively better overall mechanical properties than the pure LDPE (100/0). The calculated young's modulus value of $70 / 30$ blend was $78.89 \mathrm{~N} / \mathrm{mm}^{2}$, which was very high value compared to other compositions (Figure 1). One of the physical characteristics of miscible blends showed better mechanical properties than pure polymers. The $80 / 20,60 / 40$, and 50/50 blend compositions showed the same mechanical behaviors, i.e., they have young's modulus, and stress at peak values were higher than those of the pure polymer (100/10); while the stress at break remained almost the same as that for pure. The 50/50 composition exhibited higher stress at break.

\subsection{Rheological Measurement}

Dynamic and shear rheological measurements were carried out on a Discovery 
Table 2. Rheological parameters of LDPE and LDPE/LLDPE blends.

\begin{tabular}{ccccccccccccccc}
\hline & \multicolumn{3}{c}{ Storage Modulus (Pa) } & \multicolumn{3}{c}{ Loss Modulus (Pa) } & \multicolumn{4}{c}{ Complex Viscosity (Pa·s) } \\
\cline { 2 - 6 } & $0.1 \mathrm{rad} / \mathrm{s}$ & $1 \mathrm{rad} / \mathrm{s}$ & $10 \mathrm{rad} / \mathrm{s}$ & $\begin{array}{c}1001 \\
\mathrm{rad} / \mathrm{s}\end{array}$ & $0.1 \mathrm{rad} / \mathrm{s}$ & $1 \mathrm{rad} / \mathrm{s}$ & $10 \mathrm{rad} / \mathrm{s}$ & $\begin{array}{c}1001 \\
\mathrm{rad} / \mathrm{s}\end{array}$ & $0.1 \mathrm{rad} / \mathrm{s}$ & $1 \mathrm{rad} / \mathrm{s}$ & $10 \mathrm{rad} / \mathrm{s}$ & $\begin{array}{c}1001 \\
\mathrm{rad} / \mathrm{s}\end{array}$ \\
\hline LDPE/LLDPE-100:0 & 2237 & 10,174 & 31,809 & 78,492 & 3327 & 10,076 & 23,709 & 47,402 & 40,095 & 14,319 & 3987 & 916 \\
LDPE/LLDPE-90:10 & 1975 & 8481 & 27,143 & 71,350 & 2765 & 8575 & 21,651 & 46,301 & 33,989 & 12,061 & 3472 & 850 \\
LDPE/LLDPE-80:20 & 1848 & 8661 & 30,013 & 86,179 & 2910 & 9623 & 26,594 & 60,907 & 34,479 & 12,947 & 4010 & 1055 \\
LDPE/LLDPE-70:30 & 1414 & 6928 & 24,937 & 73,666 & 2325 & 8045 & 22,983 & 53,662 & 27,222 & 10,617 & 3391 & 911 \\
LDPE/LLDPE-60:40 & 1361 & 6493 & 23,103 & 67,555 & 2133 & 7401 & 21,018 & 48,776 & 25,306 & 9846 & 3123 & 833 \\
LDPE/LLDPE-50:50 & 1090 & 5958 & 23,734 & 78,229 & 2029 & 7767 & 24,689 & 62,796 & 23,042 & 9790 & 3424 & 1003 \\
\hline
\end{tabular}

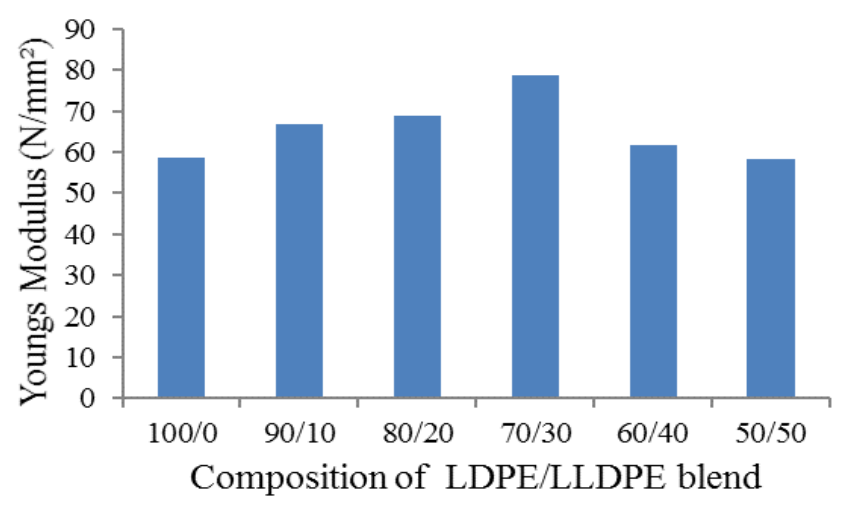

Figure 1. Variation of young's modulus with blend composition.

Hybrid Rheometer (DHR-3), in the plate-plate geometry, using plates of $25 \mathrm{~mm}$ diameter and a sample thickness of $1 \mathrm{~mm}$. The measurements were conducted under a constant temperature $180^{\circ} \mathrm{C}$, a variable frequency from 0.1 to $100 \mathrm{rad} / \mathrm{s}$, and an amplitude of deformation of $1 \%$ applied to obtain rheological parameter. The thermal stability of the selected samples was checked, the angular frequency dependence of shear storage modulus (G) and shear loss modulus ( $\left.G^{\prime \prime}\right)$ at $180^{\circ} \mathrm{C}$ is plotted in Figure 2 and complex viscosity $\left(\eta^{\star}\right)$ data tabulated in Table 2 and shown in Figure 3.

The viscosity of the polymer melt usually plays an important role in the flow properties of the material; therefore rheological measurements are extensively used to study polymer melt [8] [9]. It is observed that both storage modulus and loss modulus increased with the increase in frequency and at low frequency decrease with the increase of LLDPE content. It can be clearly noted from Figure 3 that the complex viscosity decreased with the increase of LLDPE weight percentage, this is accredited to the softening effect imposed by the LLDPE in the blend. Therefore the presence of LLDPE in the blend will induce easy process-ability which is beneficial for food packaging application

\subsection{Thermal Investigation}

Differential Scanning Calorimetry (DSC). The thermal profile (DSC) of the blends was evaluated using DSC 50 Shimadzu with a heating rate of $10 \mathrm{~K} / \mathrm{min}$ 


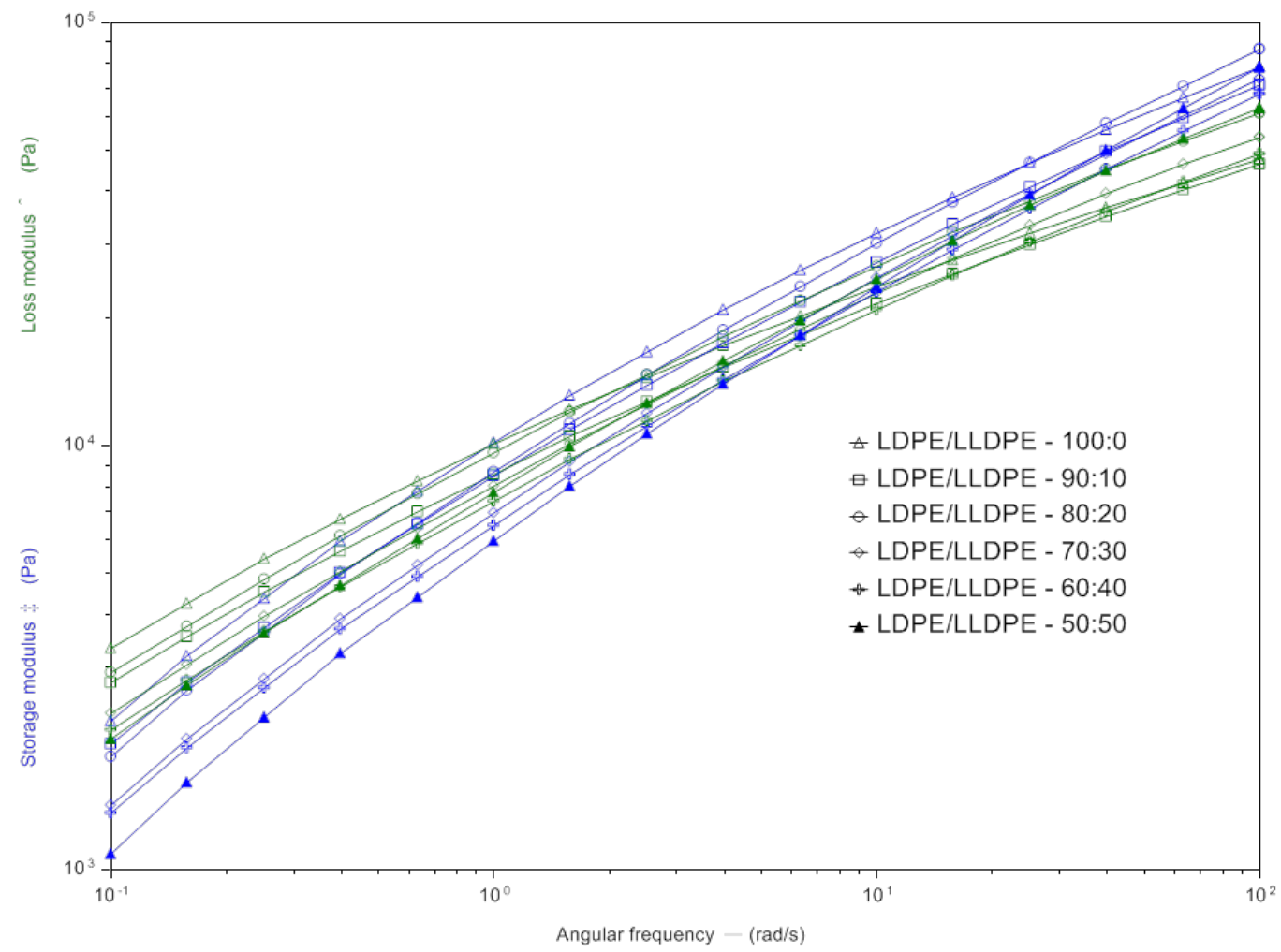

Figure 2. Variation of storage and loss modulus for Different LDPE/LLDPE blends.

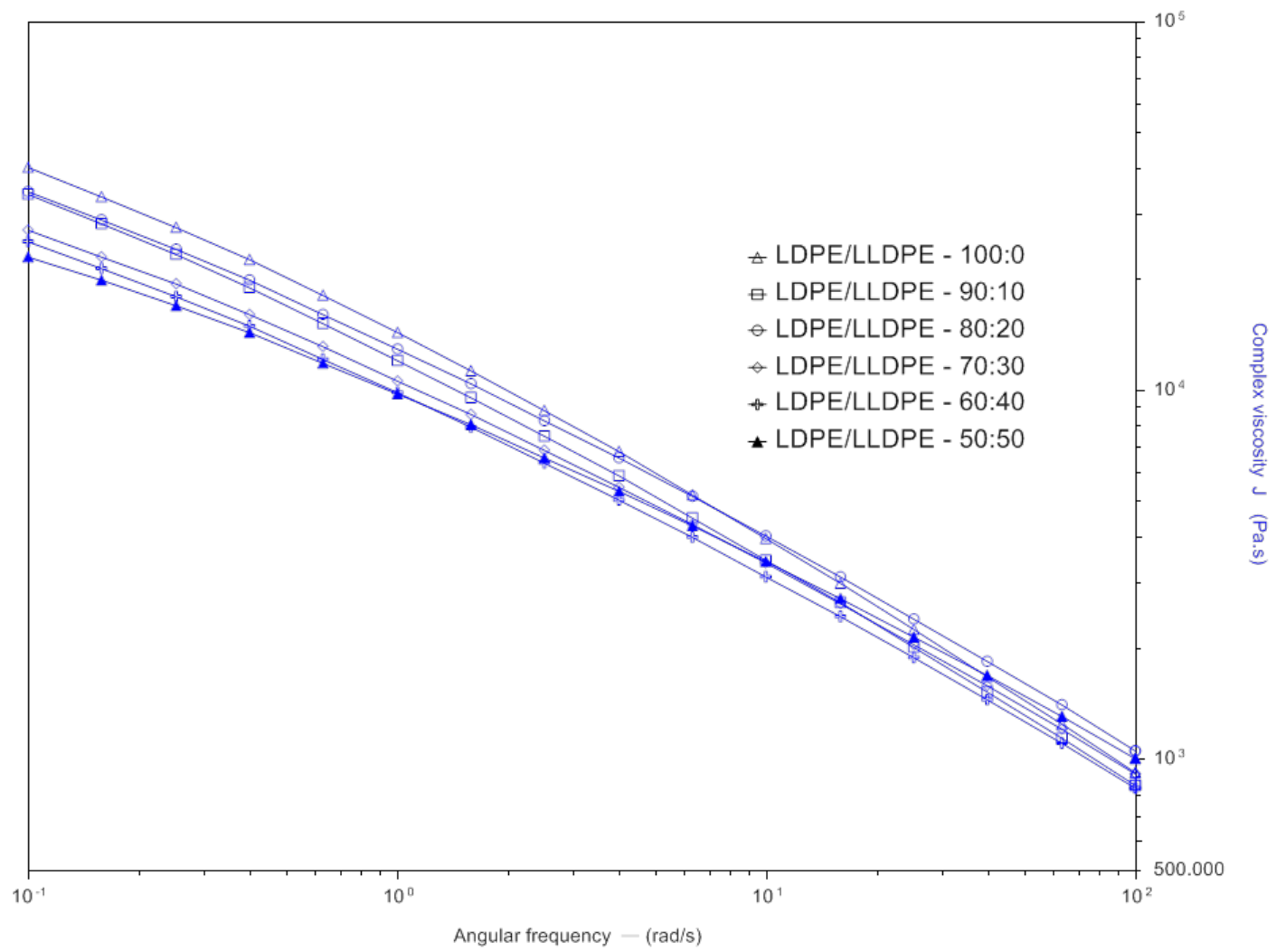

Figure 3. Complex viscosity $\left(\eta^{\star}\right)$ for different LDPE/LLDPE blends. 
starting from $-100^{\circ} \mathrm{C}$ to $250^{\circ} \mathrm{C}$. The heating and cooling curves were recorded for the evaluation of the thermal properties (Figure 2). Figure 4 shows that increasing the concentration of LLDPE to LDPE blends resulted in a homogenous mixture up to $30 \%$. With higher concentrations of LLDPE the blend starts to experience some inhomogeneous behavior and that explains the appearance of additional shoulder peak at $40 \%$ and a second peak at 50\% of LLDPE which agrees with the mechanical behavior of the blends at the same percentages. It is noted that the main melting peak remained just above $110^{\circ} \mathrm{C}$ for all selected blends and that is constituent with melting point of a polymer blend always appears between those of the individual components [10].

\section{Conclusion}

In this study the mechanical, thermal and rheological properties were investigated for different blend ratios of low density polyethylene (LDPE) and linear
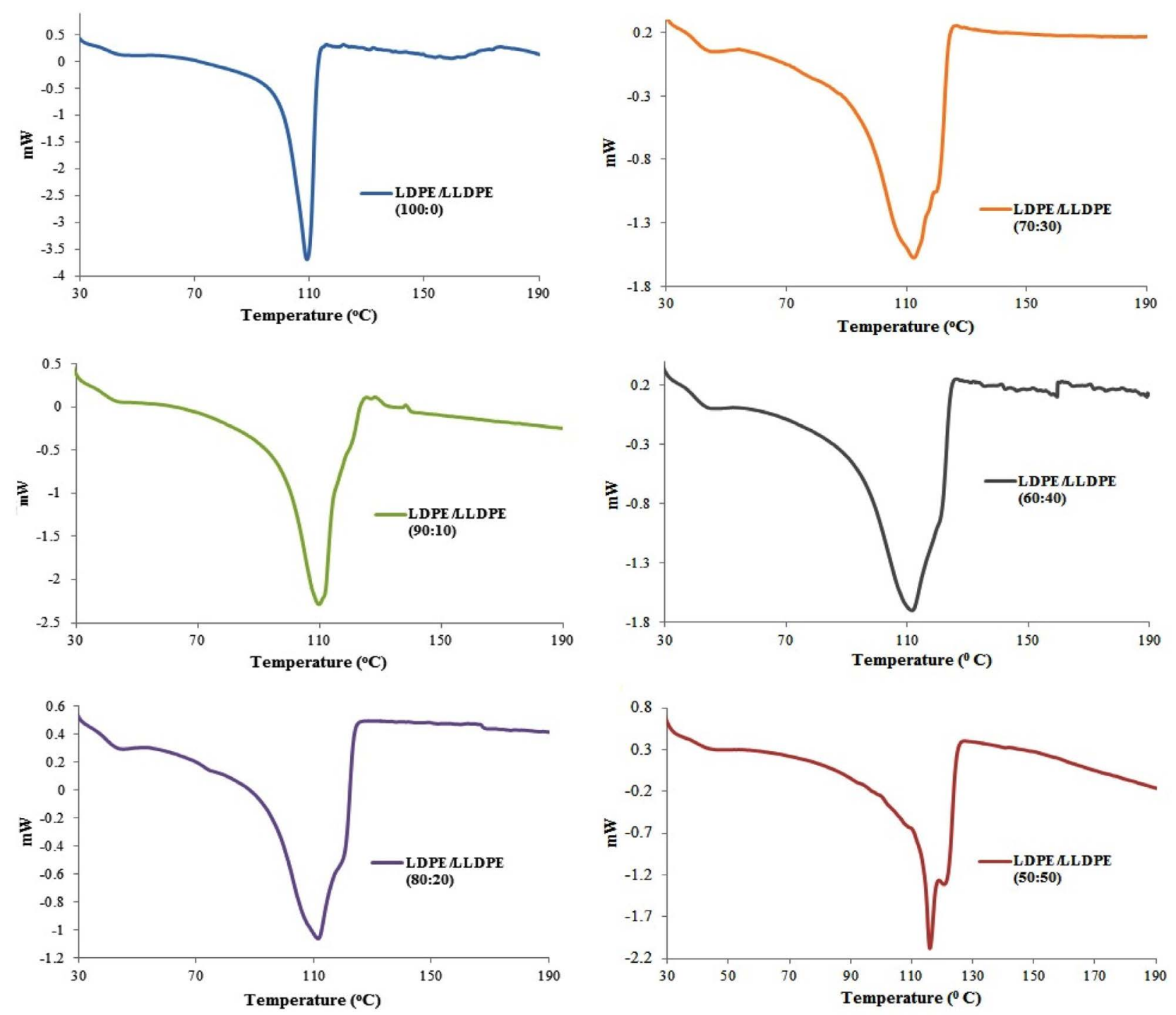

Figure 4. Differential scanning calorimetry curves of LDPE/LLDPE blends. 
low density polyethylene (LLDPE). The analysis of the DSC results for all blend ratios indicated phase separation at occurs at high concentration of LLDPE. The mechanical properties show synergetic effect on stress at peak and elongation at break. The calculated rheological parameters directed that the blend enjoy easy processing at high LLDPE weight percentage Thus, among the different blends that were investigated the blend composition LDPE/LLDPE (70/30) exhibited remarkable properties over the pure LDPE and other compositions.

\section{References}

[1] Chávez, C.C. and Soto, V.H. (2014) Morphology and Thermal Properties of a PC/PE with Reactive Compatibilization. Polymers for Advanced Technologies, 18, 439-445.

[2] Yin, B., Zhao, Y., Pan, M. and Yang, M. (2007) Morphology and Thermal Properties of a PC/PE Blend with Reactive Copatilization. Polymers for Advanced Technologies, 18, 439-445. https://doi.org/10.1002/pat.877

[3] Zhao, L. and Choi, P. (2006) A Review of the Miscibility of Polyethylene Blends. Materials and Manufacturing Process, 21, 135-142. https://doi.org/10.1081/AMP-200068644

[4] Wagner, M.H., Kheirandish, S. and Yamaguchie, M. (2004) Quantitative Analysis of Melt Elongational Behavior of LLDPE/LDPE Blends. Rheol Acta, 44, 198-218. https://doi.org/10.1007/s00397-004-0400-9

[5] Fang, Y., Carreau, P.J. and Lafleur, P.G. (2005) Thermal and Rheological Properties of mLLDPE/LDPE Blends. Polymer Engineering Science, 45, 1254-1269. https://doi.org/10.1002/pen.20401

[6] ASTM D 638 (2007) Mechanical Property. American Society for Testing and Materials, Philadelphia, Penn.

[7] ASTM D 3850-200. (2007) Thermal Property. American Society for Testing and Materials, Philadelphia, Penn.

[8] Al-Samhan, M. and Samuel, J. (2017) Comparative Effects of MMT Clay Modified with Two Different Cationic Surfactants on the Thermal and Rheological Properties of Polypropylene Nanocomposites. International Journal of Polymer Science, 2017.

[9] Yamaguchi, M. and Abe, S. (1999) LLDPE/LDPE Blends I. Rheological, Thermal and Mechanical Properties. Journal of Applied Polymer Science, 74, 3153-3159. https://doi.org/10.1002/(SICI)1097-4628(19991220)74:13<3153::AID-APP18>3.0.C O;2-T

[10] Bhardwaj, I.S., Kumar, V. and Palanivelu, K. (1988) Thermal Characterisation of ldpe and lldpe blends. Thermochimica Acta, 131, 241-246. 